\title{
Resonance Raman Spectra of Manganese-Porphyrins on Ion-Exchange Resins Exhibiting Uricase-Like Catalytic Activity1
}

\author{
Junichi Odo*, Masaki Mifune*, Akimasa Iwado*, Tatsuya Karasudani*, Hirotaka Hashimoto*, \\ Noriko MotoHaSHI**, Yoshimasa TANAKA*† and Yutaka SAITo*†† \\ *Faculty of Pharmaceutical Sciences, Okayama University, Tsushima-naka, Okayama 700, Japan \\ **Kobe Women's College of Pharmacy, Motoyamakita-machi, Higashinada, Kobe 658, Japan
}

\begin{abstract}
Ion-exchange resins modified with some manganese(III)-porphyrins $\left(\mathrm{Mn}^{3+}-\mathrm{P}_{\mathrm{r}}\right)$ show a uricase-like catalytic activity, which is applicable to the determination of uric acid. The resonance Raman spectra of $\mathrm{Mn}^{3+}-\mathrm{P}_{\mathrm{r}}$ indicate that $\mathrm{Mn}^{3+}$ porphyrins on modified resins are reduced to $\mathrm{Mn}^{2+}$-porphyrins with oxidizing uric acid; $\mathrm{Mn}^{2+}$-porphyrins then return to $\mathrm{Mn}^{3+}$-porphyrins by oxidation with $\mathrm{O}_{2}$ in the reaction system. It was concluded on the basis of these results that the modified resins show an uricase-like activity by repeating this redox cycle of manganese-porphyrins on the modified resins. $\mathrm{Mn}^{3+}-\mathrm{P}_{\mathrm{r}}$ exhibited no oxidative catalytic activity for 7 -methylated derivatives of uric acid, indicating that the nitrogen atom at the 7-position of uric acid plays an important role in the activity of $\mathrm{Mn}^{3+}-\mathbf{P}_{\mathrm{r}}$.
\end{abstract}

Keywords Modified resin, uricase-like activity, uric acid, resonance Raman spectrum, porphyrin-core vibration, manganese-porphyrin

In clinical assays, enzyme reactions catalyzed by uricase, peroxidase and catalase are frequently used as important analytical reactions. However, these enzymes have some disadvantages regarding stability, handling, purity and storage. As a study of improvement of these disadvantages, it was previously indicated that some resins modified with metallo-porphyrins exhibit such enzyme-like activities as peroxidase, catalase and uricase, and are available for clinical analyses as good mimics of these enzymes. ${ }^{2-5}$

In the present study resins modified with $\mathrm{Mn}^{3+}$ tetrakis(4-sulfophenyl)porphine and $\mathrm{Mn}^{3+}$-tetrakis(1methylpyridinium-4-yl)porphine, exhibiting a uricaselike catalytic activity, were dealt with by means of resonance Raman spectroscopy. In order to know how these modified resins act as a catalyst, the resonance Raman spectra were measured in the course of oxidizing uric acid. As the result, the uricase-like activity of the modified resins was found to be caused by a redox cycle of manganese ion.

\section{Experimental}

\section{Compounds}

Tetrakis(4-sulfophenyl)porphine (TPPS) and tetrakis(1-methylpyridinium-4-yl)porphine (TMPyP) were

\footnotetext{
† Present address: Department of Biochemistry, College of Science, Okayama University of Science, Ridai-cho, Okayama 700, Japan.

\# To whom correspondence should be addressed.
}

purchased from Tokyo Kasei Kogyo Co. Ltd. and used without further purification. Their manganese(III)complexes, $\mathrm{Mn}^{3+}$-TPPS and Mn ${ }^{3+}$-TMPyP (Fig. 1), were prepared by methods similar to those given in the literature. ${ }^{6}$ Anion-exchange (Amberlite IRA 900) and a cation-exchange (Dowex MSC-1) resins were regenerated in their chloride and sodium forms, respectively. The resins modified with manganese-porphyrins $(25 \mu \mathrm{mol} / \mathrm{g}), \mathrm{Mn}^{3+}-\mathrm{TPPS}_{\mathrm{r}}$ and $\mathbf{M n}^{3+}-\mathrm{TMPyP}$, were prepared as described before. ${ }^{6}$ All other chemicals were of reagent grade and used without further purification.

Stock solutions of the samples were prepared by dissolving uric acid (UA) or its derivatives (0.1 g, Sigma Chemical Co.) with lithium carbonate $(0.1 \mathrm{~g})$ in $100 \mathrm{ml}$ water. A buffer solution (pH 11.0) was prepared by mixing a $0.2 \mathrm{M}$ sodium carbonate solution with a $0.2 \mathrm{M}$ boric acid-0.2 $\mathrm{M}$ potassium chloride solution.
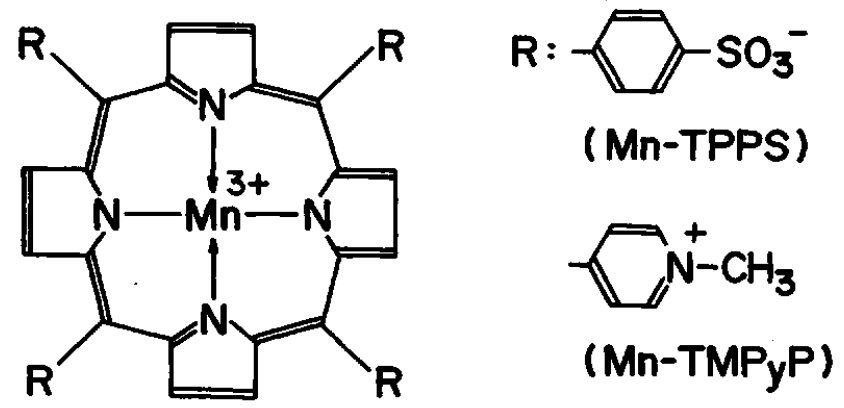

Fig. 1 Structures of manganese-porphyrins. 


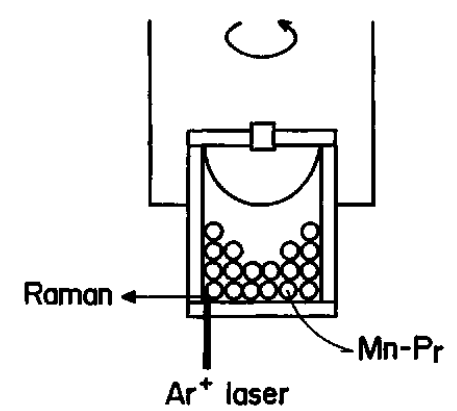

Fig. 2 Measurement method of RRS of manganeseporphyrin on modified resins.

\section{Spectral measurements}

The resonance Raman spectra (RRS) were recorded on a JASCO NR-1000 Raman spectrophotometer with a double monochromator by using $457.9 \mathrm{~nm}$ excitation from a NEC $3300 \mathrm{Ar}^{+}$-ion laser. The RRS of the $\mathrm{Mn}^{3+}$ porphyrin on the modified resins were measured by using a rotating cell in which the resins were kept in a sample solution (Fig. 2). The frequencies were calibrated using the standard bands of indene.

\section{Results and Discussion}

\section{Uricase-like catalytic activity}

When a mixture of UA solution, buffer solution

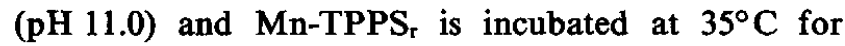
$60 \mathrm{~min}$, UA is oxidized to allantoin with hydrogen peroxide and carbon dioxide by the following reaction catalyzed by Mn-TPPS : $^{7}$

$$
\text { Uric acid }+\mathrm{O}_{2}+2 \mathrm{H}_{2} \mathrm{O} \stackrel{\text { Mn-TPPS }}{\longrightarrow} \text { Allantoin }+\mathrm{H}_{2} \mathrm{O}_{2}+\mathrm{CO}_{2} \text {. }
$$

The amount of allantoin produced was equivalent to that of UA added. ${ }^{8}$ However, the aqueous solution of $\mathrm{Mn}^{3+}$ TPPS and $\mathrm{Mn}^{3+}-$ TMPyP did not catalyze reaction (1), and no amount of UA was oxidized, suggesting that only $\mathrm{Mn}^{3+}$-porphyrins on the ion-exchange resins act as catalysis in reaction (1). In order to investigate any change of $\mathrm{Mn}^{3+}$-porphyrins on the resins, resonance Raman spectroscopy is available; ordinary Raman, IR and UV spectroscopies can not be used.

\section{Resonance Raman spectra}

The RRS of Mn-TPPS, in a buffer solution (pH 11) are shown in Fig. 3. All of the bands observed are due to $\mathrm{Mn}^{3+}$-porphyrin on the modified resin; no band of the mother ion-exchange resin was observed. As described in the proceeding 9 , RRS is essentially the same as that of an aqueous solution of $\mathrm{Mn}^{3+}$-TPPS, indicating that the structure of $\mathrm{Mn}^{3+}$-TPPS on the resin is not so different from that in an aqueous solution. Most of the resonance Raman band can be assigned to porphyrin-

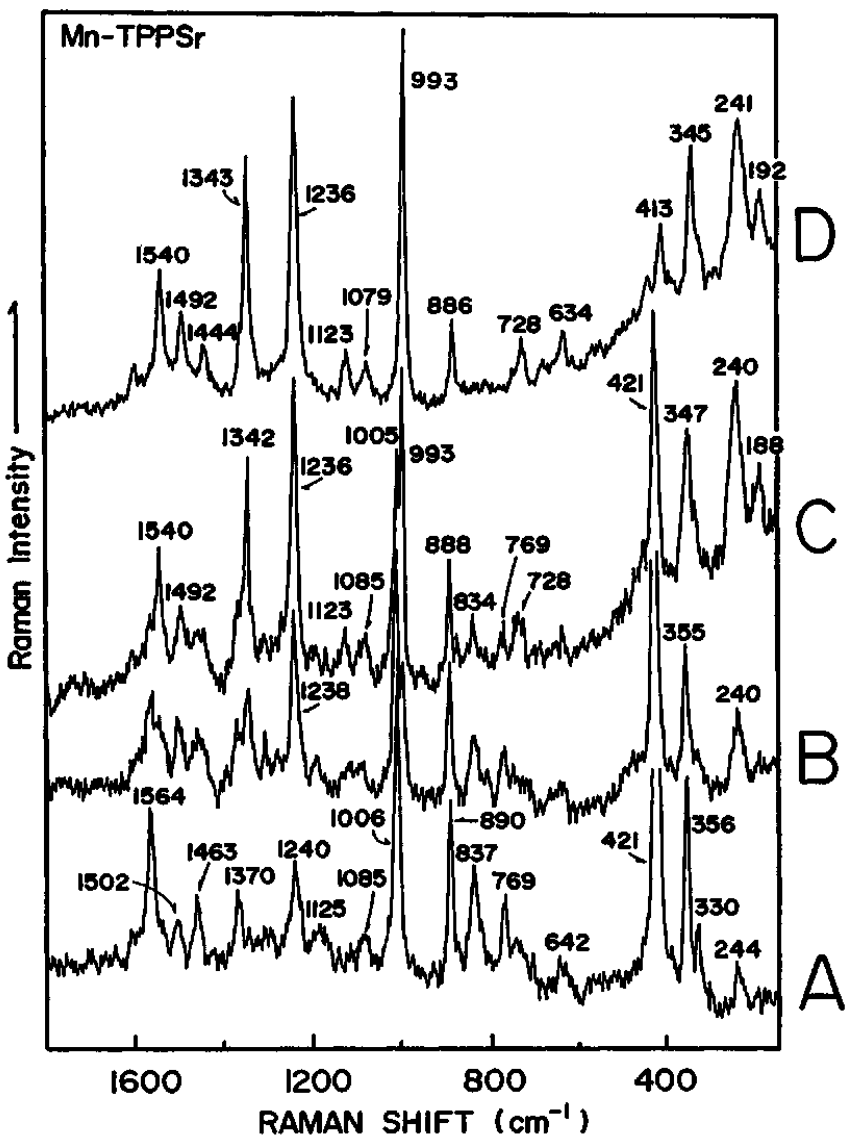

Fig. 3 RRS of Mn-TPPS in the course of the oxidation of UA. (A): before the addition of UA; (B) and (C): 5 and 20 min after the addition of UA, respectively; (D): treated with sodium dithionite.

core vibrations by refering to the assignment for related compounds $^{10,11}$ (Table 1). After the addition of UA, new bands at 993,1342 and $1540 \mathrm{~cm}^{-1}$ were especially observed in the RRS, even after $5 \mathrm{~min}$; the relative intensities of these bands increased with the incubation time. On the contrary, the intensities of the bands at 1564, 1370 and $1006 \mathrm{~cm}^{-1}$ decreased relatively with progress of the reaction. This result indicates that the band of $\mathrm{Mn}^{3+}$-TPPS at 1564,1370 and $1006 \mathrm{~cm}^{-1}$ are replaced by the bands at 1540,1342 and $993 \mathrm{~cm}^{-1}$, respectively, with the oxidation of $\mathrm{UA}$; also, the structure of $\mathrm{Mn}^{3+}$-TPPS on the resin changes to a compound which is characterized by resonance Raman bands at 1540, 1342 and $993 \mathrm{~cm}^{-1}$. In addition, the existence of these resonance Raman bands suggests that the compound has an absorption band to resonance with an excitation laser line around that of $\mathrm{Mn}^{3+}$-TPPS; that is, the structure of the compound is essentially similar to $\mathrm{Mn}^{3+}$ - TPPS. By assignments of metal-tetraphenylporphine ${ }^{10,12}$, the bands of physiological Hemes and $\mathrm{Fe}^{3+}$-porphyrin around 1560 , 1370 and $1010 \mathrm{~cm}^{-1}$ have been assigned to the core vibrations for the porphyrin ring; the band around $1370 \mathrm{~cm}^{-1}$ is attributed to a well-known as "oxidation state marker band", shifting to the lower frequency 
Table 1 Resonance Raman frequencies and band assignments for Mn-TPPS, and Mn-TMPyP

\begin{tabular}{|c|c|c|c|c|c|c|}
\hline $\mathrm{Mn}^{3+}-\mathrm{TPPS}_{\mathrm{r}}$ & $\mathrm{Mn}^{-T P P S} \mathrm{r}+\mathrm{UA}$ & $\mathrm{Mn}^{2+}-\mathrm{TPPS}_{\mathrm{r}}$ & $\mathrm{Mn}^{3+}-\mathrm{TMPyP} \mathrm{P}_{\mathrm{r}}$ & Mn-TMPyPr + UA & $\mathrm{Mn}^{2+}-\mathrm{TMPyP} \mathrm{P}_{\mathrm{r}}$ & Assignment ${ }^{a}$ \\
\hline$-{ }^{b}$ & - $^{b}$ & $-^{b}$ & 908 & 907 & 907 & $\delta_{s}$ (por) \\
\hline$-^{b}$ & $-^{b}$ & ${ }^{b}$ & 975 & 972 & $-b$ & \\
\hline$-^{c}$ & $993^{d}$ & 993 & -c $^{c}$ & $1000^{d}$ & 1000 & $\nu_{\mathrm{s}}\left(\mathrm{C}_{\alpha}-\mathrm{C}_{\mathrm{m}}\right)$ \\
\hline 1006 & $1005^{e}$ & $-^{c}$ & 1014 & $1014^{e}$ & $-^{\mathbf{c}}$ & $\nu_{\mathrm{s}}\left(\mathrm{C}_{\alpha}-\mathrm{C}_{\mathrm{m}}\right)$ \\
\hline 1085 & 1085 & 1079 & 1100 & 1097 & 1097 & $\delta_{s}\left(C_{\beta}-H\right)$ \\
\hline 1125 & 1123 & 1123 & 1187 & 1190 & 1191 & $\delta$ (phenyl) \\
\hline - $^{\mathrm{b}}$ & -6 & $-\mathrm{b}$ & 1220 & 1220 & 1219 & $\delta$ (phenyl) \\
\hline 1240 & 1236 & 1236 & 1255 & 1257 & 1255 & $\delta\left(C_{m}-\right.$ phenyl $)$ \\
\hline - b & $-^{b}$ & - b & 1302 & 1300 & $-\mathrm{b}$ & $\nu_{\text {as }}\left(\mathrm{C}_{\alpha}-\mathrm{C}_{\beta}\right)$ \\
\hline $\mathbf{c}^{\mathrm{c}}$ & $1342^{d}$ & 1343 & 1345 & $1345^{d}$ & 1344 & $\nu_{\mathrm{s}}\left(\mathrm{C}_{\alpha}-\mathrm{N}\right)$ \\
\hline 1370 & $1365^{e}$ & -c $^{\mathrm{c}}$ & 1370 & $1370^{e}$ & $-^{c}$ & $\nu_{s}\left(\mathrm{C}_{\alpha}-\mathrm{N}\right)$ \\
\hline$-\mathbf{b}$ & $-b$ & $-^{b}$ & 1410 & 1417 & $-^{b}$ & \\
\hline 1463 & 1450 & 1444 & 1465 & 1465 & 1445 & $\nu_{\mathrm{s}}\left(\mathrm{C}_{\alpha}-\mathrm{C}_{\beta}\right)$ \\
\hline 1502 & 1492 & 1492 & - b & - $^{\mathbf{b}}$ & ${ }^{b}$ & $\nu_{\text {as }}\left(\mathrm{C}_{\beta}-\mathrm{C}_{\beta}\right)$ \\
\hline$-^{c}$ & $1540^{d}$ & 1540 & $-^{c}$ & $1548^{d}$ & 1547 & $\nu_{\mathrm{s}}\left(\mathrm{C}_{\beta}-\mathrm{C}_{\beta}\right)$ \\
\hline 1564 & $1562^{\mathrm{e}}$ & $-c^{c}$ & 1570 & $1570^{\circ}$ & $-^{c}$ & $\nu_{\mathrm{s}}\left(\mathrm{C}_{\beta}-\mathrm{C}_{\beta}\right)$ \\
\hline 1600 & 1602 & 1600 & 1646 & 1645 & 1644 & phenyl \\
\hline
\end{tabular}

a. $\delta$, deformation; $\nu$, stretching; $\mathrm{s}$, symmetric; as, asymmetric; phenyl, pyridinium ring for Mn-TMPyP $\mathrm{P}_{\mathrm{r}}$ and phenyl ring for

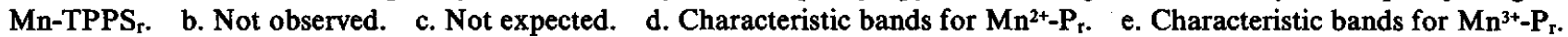

region by about $20 \mathrm{~cm}^{-1}$ with the reduction of $\mathrm{Fe}^{3+}$-porphyrins to $\mathrm{Fe}^{2+}$-porphyrins. ${ }^{13}$ By analogy with these points, the shift of the $1370 \mathrm{~cm}^{-1}$ band to $1342 \mathrm{~cm}^{-1}$ suggests that an oxidation state of $\mathrm{Mn}^{3+}$ atom of $\mathrm{Mn}-$ TPPS $_{\mathrm{r}}$ may reduce to $\mathrm{Mn}^{2+}$ state in the course of the oxidation of UA. In order to confirm the reduction of the $\mathrm{Mn}^{3+}$ ion, the RRS of $\mathrm{Mn}^{2+}-\mathrm{TPPS}_{\mathrm{r}}$ reduced chemically with sodium dithionite was measured. As can be seen in Fig. 3, it is obvious that the bands at 993, 1342 and $1540 \mathrm{~cm}^{-1}$ (assigned to the core vibrations, as summarized in Table 1) are characteristic for $\mathrm{Mn}^{2+}$ TPPS, indicating that the resulting compound on the resin with oxidation of UA should be $\mathrm{Mn}^{2+}$-TPPS. It is of interest that the oxidation marker band at $1342 \mathrm{~cm}^{-1}$ is lower by about $20 \mathrm{~cm}^{-1}$ than that of $\mathrm{Mn}^{3+}$-TPPS similar to the case of Fe-porphyrins. It has thus been apparent that $\mathrm{Mn}^{3+}$-TPPS on the modified resin was reduced to $\mathrm{Mn}^{2+}-$ TPPS along with the oxidation of UA.

After completing the oxidation of UA, the characteristic bands at 993,1342 and $1540 \mathrm{~cm}^{-1}$ for $\mathrm{Mn}^{2+}-$ TPPS gradually decrease and the $\mathrm{Mn}^{3+}$-TPPS bands at 1000 , 1370 and $1564 \mathrm{~cm}^{-1}$ increase, replacing the $\mathrm{Mn}^{2+}$ TPPS band. Finally, the spectra perfectly returned to that of $\mathrm{Mn}^{3+}-\mathrm{TPPS}_{\mathrm{r}}$. Accordingly, it is clear that $\mathrm{Mn}^{2+}$-TPPS $\mathrm{r}$ reduced by UA was then oxidized to $\mathrm{Mn}^{3+}$ TPPS $_{\mathrm{r}}$ with oxygen in the reaction system. These results indicate that the uricase-like activity of $\mathrm{Mn}$ TPPS $\mathrm{r}_{\mathrm{r}}$ is based on the cycle of from $\mathrm{Mn}^{3+}$-TPPS $\mathrm{S}_{\mathrm{r}}$ to first $\mathrm{Mn}^{2+}-$ TPPS $_{\mathrm{r}}$, and then to $\mathrm{Mn}^{3+}-$ TPPS $_{\mathrm{r}}$. Since the oxidation reaction of $\mathrm{Mn}^{2+}$ on the resin is rapid, $\mathrm{Mn}^{3+}$ always exists in the reaction system. This is a reason why the RRS of $\mathrm{Mn}^{3+}-$ TPPS $_{\mathrm{r}}$ in the presence of UA could not change completely to that of $\mathrm{Mn}^{2+}-$ TPPS $_{\mathrm{r}}$.

The spectra obtained for $\mathbf{M n}^{3+}-\mathrm{TMPyP}_{\mathrm{r}}$ are shown in Fig. 4. New bands at 1000,1344 and $1547 \mathrm{~cm}^{-1}$ were

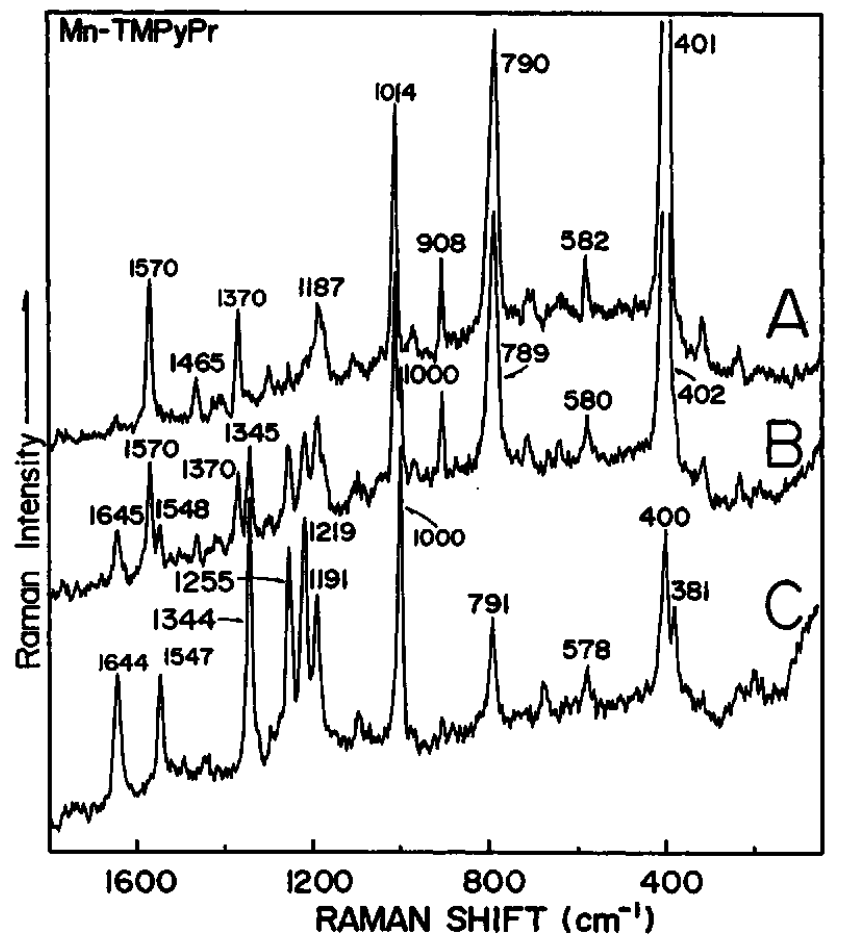

Fig. 4 RRS of Mn-TMPyP ${ }_{r}$ in the course of the oxidation of UA. (A) and (B): before and after the addition of UA, respectively; $(C)$ : treated with sodium dithionite.

observed after the addition of UA (in analogy with the case of Mn-TPPS ); they have been assigned to the porphyrin-core vibrations (Table 1). Especially, the band of $\mathrm{Mn}^{3+}$-TMPyP at $1370 \mathrm{~cm}^{-1}$, assignable to the oxidation state marker band, showed a large shift of 
$26 \mathrm{~cm}^{-1}$ upon the oxidation of UA, suggesting that $\mathrm{Mn}^{3+}$ is reduced by UA. Comparing these spectra with that of $\mathrm{Mn}^{2+}-\mathrm{TMPyP}_{\mathrm{r}}$ obtained by a chemical reduction of $\mathrm{Mn}^{3+}-\mathrm{TMPyP}_{\mathrm{r}}$ with sodium dithionite, the newly observed bands are characteristic for $\mathrm{Mn}^{2+}$-TMPyPr. Considering these spectral changes, it is clear that $\mathrm{Mn}$ $\mathrm{TMPyP}_{\mathrm{r}}$ also exhibits catalytic activity by a similar redox cycle as that in the case of Mn-TPPS .

As described above, the uricase-like activity of $\mathrm{Mn}^{3+}$ TPPS $_{\mathrm{r}}$ is due to a redox reaction of manganese ion, as summarized in the following reaction:

$$
\text { Uric acid }+\mathrm{O}_{2}+2 \mathrm{H}_{2} \mathrm{O} \underset{\mathrm{O}_{2}}{\stackrel{\mathrm{Mn}^{3+}-\mathrm{P}_{\mathrm{r}} \mathrm{Mn}^{2+}-\mathrm{P}_{\mathrm{r}}}{\longrightarrow} \text { Allantoin }}+\mathrm{H}_{2} \mathrm{O}_{2}+\mathrm{CO}_{2} \text {. }
$$

\section{Resonance Raman spectra of $M n-P_{r}$ with axial ligands}

The interference of foreign substances on the uricaselike activity was examined after incubation for $10 \mathrm{~min}$ at $35^{\circ} \mathrm{C}$ by measuring any decrease in the absorbances at $293 \mathrm{~nm}$ of mixtures of a UA solution $(110 \mu \mathrm{g}), 0.1 \mathrm{ml}$; a buffer solution ( $\mathrm{pH} 11), 4 \mathrm{ml}$; and $M \mathrm{Mn}-\mathrm{TMPyP} \mathrm{P}_{\mathrm{r}}, 20 \mathrm{mg}$. As shown in Table 2, citrate and EDTA ions inhibited the activity. The RRS of Mn-TPPS r $_{r}$ and $M n-T M P y P_{r}$ were measured in the presence of either citrate or EDTA ion. However, these substances do not show any apparent influence on the RRS of Mn-TPPS ${ }_{\mathrm{r}}$ and MnTMPyP $_{r}$; no evidence for the coordination of these substances was observed in the RRS.

\section{Catalytic activity for $U A$ derivatives}

In order to examine the oxidative catalytic activity of Mn- $P_{r}$ for UA derivatives, the RRS of Mn-TPPS $S_{r}$ and Mn-TMPyP ${ }_{r}$ were measured in the presence of UA derivatives. The catalytic activity was estimated by measuring especially the porphyrin-core vibration bands,

Table 2 Effects of axial ligands

\begin{tabular}{lcc}
\hline Substance & $\begin{array}{c}\text { Final concentration/ } \\
10^{-4} \mathrm{M}\end{array}$ & $\begin{array}{c}\text { Changed uric acid } \\
\%\end{array}$ \\
\hline (None) & 100 & 100 \\
Pyridine & 100 & 100 \\
Imidazol & 100 & 96 \\
Na azide & 100 & 99 \\
Na cyanide & 100 & 98 \\
Na oxalate & 100 & 94 \\
Na acetate & 100 & 100 \\
Na lactate & 100 & 96 \\
Na citrate & 100 & 59 \\
& 50 & 74 \\
& 10 & 83 \\
Na EDTA & 100 & 27 \\
& 10 & 45 \\
& 1 & 61
\end{tabular}

a. Concentration of uric acid: $1.1 \times 10^{-4} \mathrm{M}$.

b. Sodium ethylenediamine tetraacetate.
Table 3 Uricase-like activity for uric acid and its derivatives

\begin{tabular}{|c|c|c|c|c|}
\hline \multirow{2}{*}{$\begin{array}{l}\text { Uric acid \& } \\
\text { its derivatives }\end{array}$} & \multicolumn{2}{|c|}{ UV method ${ }^{a}$} & \multicolumn{2}{|c|}{ RRS method ${ }^{b}$} \\
\hline & $\mathbf{A}^{\mathbf{c}}$ & $\mathbf{B}^{\mathbf{c}}$ & $A^{c}$ & $\mathbf{B}^{\mathbf{c}}$ \\
\hline (None) & - & - & 0 & $0.2^{\mathrm{d}}$ \\
\hline Uric acid (UA) & 0 & 0 & 3.2 & 1.6 \\
\hline 1-Methyl-UA & 0 & 0 & 3.1 & 1.5 \\
\hline 3-Methyl-UA & 11 & 26 & 2.6 & 1.0 \\
\hline 9-Methyl-UA & 65 & 42 & 1.9 & 0.9 \\
\hline 7-Methyl-UA & 99 & 93 & 0 & 0.2 \\
\hline 1,7-Dimethyl-UA & 100 & 98 & 0 & 0.2 \\
\hline 3,7-Dimethyl-UA & 100 & 95 & 0 & 0.2 \\
\hline 1,3,7-Trimethyl-UA & 100 & 94 & 0 & 0.2 \\
\hline
\end{tabular}<smiles>O=c1[nH]c(=O)c2[nH]c(=O)[nH]c2[nH]1</smiles>

a. Ratio (\%) of the amount of the unchanged UA derivatives to that of the UA derivatives added.

b. Ratio of the intensity of the band at $1342 \mathrm{~cm}^{-1}$ for $\mathrm{Mn}$ TPPS $_{\mathrm{r}}\left(1344 \mathrm{~cm}^{-1}\right.$ for Mn-TMPyP $\left.\mathrm{P}_{\mathrm{r}}\right)$ to the intensity of the band at $1370 \mathrm{~cm}^{-1}$.

c. Resin: A, Mn-TPPS $;$; , Mn-TMPyP $P_{r}$.

d. A weak band is observed at $1344 \mathrm{~cm}^{-1}$ for $\mathrm{Mn}^{3+}-\mathrm{TMPyP}$.

which are characteristic for $\mathrm{Mn}^{2+}-\mathrm{TPPS}_{\mathrm{r}}$. In the case of 9-methyl-UA, these characteristic bands for $\mathrm{Mn}^{2+}-\mathrm{P}_{\mathrm{r}}$ were obtained, but not in the case of 7-methyl-UA. This result indicates that $\mathrm{Mn}^{3+}-\mathrm{TPPS}_{\mathrm{r}}$ shows catalytic activity for 9-methyl-UA but not for 7-methyl-UA. However, in both the cases, no difference in RRS from those in the case of UA was observed. The results obtained for other UA derivatives with $\mathrm{Mn}^{3+}$-TPPS $\mathrm{r}$ and $\mathrm{Mn}^{3+}$ TMPyP $_{\mathrm{r}}$ are summarized in Table 3. As can be seen, the characteristic bands for $\mathrm{Mn}^{2+}-\mathrm{TPPS}_{\mathrm{r}}$ and $\mathrm{Mn}^{2+}$ TMPyP $P_{r}$ were measured for UA and 1-, 3- and 9-methyl$\mathrm{UA}$, indicating that $\mathrm{Mn}^{3+}-\mathrm{TPPS}_{\mathrm{r}}$ and $\mathrm{Mn}^{3+}-\mathrm{TMPyP}_{\mathrm{r}}$ shows catalytic activity for these UA derivatives. In order to confirm these oxidative activities for the UA derivatives, the decreases of the UA derivatives after incubation with $\mathrm{Mn}^{3+}-\mathrm{P}_{\mathrm{r}}$ were measured by the UV method, similarly to an examination of uricase-like activity. ${ }^{14}$ These results are shown in Table 3. In agreement with the result of RRS, 1-, 3- and 9-methyl-UA were oxidized but not 7-methylated UA derivatives, 7methyl-, 1,7-dimethyl-, 3,7-dimethyl- and 1,3,7trimethyl-UA. This result corresponds to that obtained by the Raman method.

As discussed above, it is clear that $\mathrm{Mn}^{3+}-\mathrm{TPPS}_{\mathrm{r}}$ and $\mathrm{Mn}^{3+}-\mathrm{TMPyP}_{\mathrm{r}}$ show no catalytic oxidative activity for the 7-methylated derivatives of UA. This result indicates that the nitrogen atom at the 7-position of UA plays an important role in the oxidation of UA with modified resins.

This work was supported by a Grant-in-Aid for Scientific Research from the Ministry of Education, Science and Culture, Japan. 


\section{References and Notes}

1. A part of this work was presented at the 109th Annual Meeting of Pharmaceutical Society of Japan, Nagoya, 1989 and at the 4th Symposium on Roles of Metals in Biological Reactions, Biology and Medicine, Tokyo, 1989.

2. Y. Saito, M. Mifune, T. Kawaguchi, J. Odo, Y. Tanaka, M. Chikuma and H. Tanaka, Chem. Pharm. Bull., 34, 2885 (1986).

3. Y. Saito, M. Mifune, S. Nakashima, J. Odo, Y. Tanaka, M. Chikuma and H. Tanaka, Anal. Sci, 3, 171 (1987).

4. Y. Saito, M. Satouchi, M. Mifune, T. Tai, J. Odo, Y. Tanaka, M. Chikuma and H. Tanaka, Bull. Chem. Soc. Jpn., 60, 2227 (1987).

5. Y. Saito, M. Mifune, S. Nakayama, J. Odo, Y. Tanaka, M. Chikuma and H. Tanaka, Talanta, 34, 667 (1987).

6. Y. Saito, S. Nakayama, M. Mifune, J. Odo, Y. Tanaka, M. Chikuma and H. Tanaka, Anal. Chim. Acta, 172, 285 (1985).

7. The decomposition of UA was confirmed by measuring the decrease of the absorbance at $\lambda_{\max }(293 \mathrm{~nm})$ of UA and the reaction product was identified as allantoin based on the comparison of IR and ${ }^{1} \mathrm{H}-\mathrm{NMR}$ spectral data with the reported data.

8. The amount of allantoin was measured by the method of the following literature. H. Yuki, T. Yajima and $H$. Kawasaki, Chem. Pharm. Bull., 28, 3375 (1980).

9. Y. Saito, M. Mifune, T. Karasudani, A. Taguchi, Y. Tanaka, M. Chikuma and H. Tanaka, J. PharmacobioDyn., 10, s-6 (1987).

10. J. M. Burke, J. R. Kincaid and T. G. Spiro, J. Am. Chem. Soc., 100, 6077 (1978).

11. N. Blom, J. Odo, K. Nakamoto and D. P. Strommen, $J$. Phys. Chem., 90, 2847 (1986).

12. P. Stein, A. Ulman and T. G. Spiro, J. Phys. Chem., 88, 369 (1984).

13. K. Nakamoto, "Infrared and Raman Spectra of Inorganic and Coordination Compounds", 4th ed., pp. 213-221 and 414-417, Wiley-Interscience, New York, 1986.

14. M. Mifune, J. Odo, N. Motohashi, A. Iwado, Y. Saito, M. Chikuma and H. Tanaka, Talanta, in press.

(Received January 28, 1991)

(Accepted April 15, 1991) 